published in 1843. Du Bois speaks of " transverse cut, natural or artificial," instead of internal surface - of "longitudinal cut" instead of external surface; and so, according to his experiments, he very happily generalises the expressions of Matteucci, confirming at the same time the immediate results of his researches.

After the discovery of the muscular current Matteucci had to acknowledge that very many of the phenomena he had hitherto derived from the "current proper" belong to the muscular current. Analysis of facts showed him that, conformably with the views of $\mathrm{Du} B$ ois, in nearly all animals the muscular current suffices to explain all the phenomena he had observed, and that, strictly speaking, the frog alone evinces phenomena which seem to require for their explanation a "current proper" besides the muscular current.

It was not without hesitation that Matteucci brought himself to attribute all the phenomena to the muscular current. Up to 1845 he had resolved to save the "current proper" of the frog at least for the frog itself, and the subsequent history of animal electricity has shown that Matteucei was not badly guided by his instinct. It is now proved that in reality the current which Nobili and Matteucci had primarily called "proper" to the frog is, in fact, proper to that and to some other animals-that it does not proceed from the muscles, but that it is produced in the skin. In this view the frog really possesses at least two kinds of currents, as Matteucei had for a long time maintained : the current of the skin and the current of the muscles.

If it has not been given to Matteucci to discover the alteration of the muscular current which accompanies the contraction of the muscle, he has aligbted on a curious and interesting phenomenon which stands in close relation with the oscillations of the current in the contraction-the "contraction," I mean, which he has called "induced." The fact consists in this: that if a frog's nerve is extended upon the length of the muscle of another frog, every time that this muscle contracts the nerve becomes irritated in such a manner as to induce secondary contraction of the muscles which stand in relation with this nerve. A third nerve may be extended over the muscle of the second frog, and in this way induce tertiary contraction or quaternary, \&c. This singular phenomenon has all the appearance of an electric irritation, but some experiments undertaken to test the hypothesis of an electric origin of the contraction in question did not give Matteucci all the certainty which appeared to him necessary to affirm decisively that the phenomenon is the effect of an electric variation in the muscle. To-day it is no longer doubted that a rapid diminution in the muscular current of the "inducent" frog -a diminution which exists during the contraction-is the cause of the so-called induced contraction of Matteucci.

No one can occupy himself with the production of electricity in the animal body without taking into consideration the electric fishes, in which the electro-motor power is found developed to a high degree. With these Matteucci often and deeply busied himself, examining the discharge of the torpedo with all the means then available of physics. Linari, with the aid of Matteucci, has succeeded in drawing the electric spark from the torpedo. Savi, at Matteucci's instance, has given us a magnificent anatomical description of the nervous centres and of the electric organ of this fish, and Matteucci was thus enabled to win appreciation of the analogy which exists between this organ and the muscle-an analogy already vaguely surmised in past ages, according to which these electric organs were musculi falcati (scythe-shaped muscles). Matteucci hoped that a more minute microscopic analysis of the electric organ might yield still etronger support to this analogy; and this analysis, made but recently by Wagner, Valentin, and the other day by Boll and Ciaccio, has not falsified his expectation-at least in all that relates to the distribution of the nerves.

We have still to speak of the last works of Mattencei which treat of the polarisation of the nerves. In the second part of the third series of the "Memorie della Società dei XI.," 1868 , p. 93, we find a memoir of his "Sulla teoria fisica dell' elettrotono dei Nervi," which contains, not all indeed, bat the principal part of these researches. They give a very ingenious explanation of the phenomenon which, discovered by $\mathrm{Da}$ Bois, and described under the name of electrotone, was for some time regarded as a mysterious product of the particular structure of the nerves.

It is true, as Du Bois has already observed, that, among all the known organic tissues, the nerve alone shows the phenomenon described as electrotone, but it is an exaggeration to believe that these phenomena do not yield to physical analysis. Matteucci has proved that the electrotone, far from being uselessly connected with the functional property of the nerve, may be considered as a secondary current produced by the electrolyses which are deposited at various points when a constant current runs along it-on condition of that being admitted which had long been probable-viz., that the axis-cylinder of the nerve is a much more perfect conductor of electricity than its surrounding medulla, which has all the appearance of an oily liquid. Not content with theory, Matteucci demonstrated by experiment that every cylinder composed of a central nucleus, which is a good conductor of electricity, and of an electrolyte of great resistance, as a peripheral stratum shows all the characteristic phenomena of the electrotone if the central conductor is polarisable in the electrolytic solution.

In other works on the same theme, Matteucci has developed yet further results, which were the fruit of these researches on the secondary polarisation.

It cannot be said that these latest works of Matteucci were received with much applause on their first publication. Too pronounced was the antagonism in which he placed himself with generally accredited opinion, and too simple appeared the explanation proposed by him; because, if true, it would have had to remain concealed for so long a time, in spite of the interest which the electrotone had awakened among the cultivators of electro-physiology, the ranks of whom were every year increasing. But Matteucci could still see the triumph of his doctrine. His experiments were repeated, his findings confirmed, now observations poured in to substantiate his own, and to-day we can class these latest works of Matteucci on the secondary polarity as among the most meritorious which exist in the field of electro-physiology.

\section{ON THE EQUALISATION OF LIGHT IN HOSPITALS AND ROOMS.}

B× ROBERT MALLET, Esq., C.E.

THE temperature of inhabited rooms has been rendered equable by means of the thermostat in connexion with a source of artificial heat and by other means, but no attempt that I am aware of has ever been made to devise apparatus by means of which the light which enters apartments, and more especially the wards of ophthalmic hospitals, might be rendered nearly uniform, whatever were the variations occurring in the amount of light at any moment coming from the sun. This varies not only with the period of the day or year, and with the serenity or obscurity of the sky. but also with every passing cloud; and in London, in the spring of the year especially, the constant transit over a sunlit sky of huge masses of opaque cumulous clouds, whose production is perbaps due to the wind setting over the hilly country which more or less surrounds the metropolis, produces a constant and rapid fluctuation of light, distressing to a bealthy eye, and injurious to one diseased or overworked. This fluctuating light, which penetrates every apartment, is not, I believe, guarded against in the ophthalmic wards of any hospital in London, by any but the ineffectual provision of two sets of window-blinds, one set being quite opaque, the other of the ordinary white calico sunlight filtered through which is, like the light passed through ground glass, distressing to all eyes. Though the production of a photostat, or apparatus for equalising the admission of daylight, is a much more delicate problem than that of the thermostat, it seems to me that in the present state of physical science the means may be devised for effecting the object sufficiently nearly for practical purposes, and I venture to recommend its consideration more especially to our electrical engineers or physicists. The problem can only be solved experimentally, and not without 
the expenditure of thought, time, and labour, which, however, would in the end, probably well reward the successtul inventor; for uniformity of light, if once attained by means neither very complicated nor expensive, would be adopted, not only in hospitals, \&c., but eagerly sought for as an applianco in all libraries, reading-rooms, public offices, and the private studies of the richer classes. Snmething of the line of thought that may eventuate in this may be roughly sketched.

It may be assumed, as sufficiently near the truth, that. whether the sky be cloudy or serene and the light bright or combre, the proportion letween the luminous and the heat rays received at any moment of the day upon a unit of surface will be approximately the same. We might therefore employ the heat rays as the means of regulating those of light. If a large parabolic reflector, placed in a glass chamber, be mounted heliostatically, or so that it shall always face the direction of the sun, whether its disc be visible or not, and in its focus, where the parallel rays of the sunlight or daylight received by it converge, a thermopile be placed, we shall be in possession of a first mover, very small in power, indeed, but still sufficient, by a suitable intermediate train of apparatus, to maintain the necessary motions in the window.blinds, constructed of inclined parallel strips, upon the principle of those now well known which are called "belioscene blinds." The feeble current, ever varying with the intensity of external ligbt, would be sufficievt to move, more or less in a rotary direction, the card or index of a large galvanometer. If we imagine, at any one point of its circumference, a source of nearly constant heat, guch as a Bunsen's burner, to be carried in one direction or the otber ly the motion of the galvanometer, we should possess the means of carrying this into greater or less proximity, or beneath a greater or less length of a componnd thermostat bar formed of steel and zine. The bending of this bar more or less hy the d fference in dilatation of the two metals would afford sufficient range and mechanical energy to he directly applied through the intervention of an adjustable rod to any one, and therefore to all, of the connected shades or slips of the helinscene blinds. Euch slip heing light, balanced npon its small horizontal axis, and having extremely little friction or inertia, a very small mechinical $\mathrm{fffort}$ would suffice for changing the angle of hundreds of these shades so that the interstitial sra.es admitting light from the outside should vary inversely as the intensity if the light to which they gave passage, and so the light within the apartment remain practically constant.

Many other analogous arrangements will occur to phy. sicists and merbanicians accustomed to deal with the innumerable, delicate, and beautiful, though now common contrivances, by which electricity, heat, and light have been made subservient to our wants, and to such men I leave the pursuit of my rongh suggestion, of which $I$ am never likely to be able myself to attempt the realisation.

Perbaps, instead of the thermopile, an entirely different source of motion might be devised, based upon the curious difference in the electro-conductivity of selenium, dependent upon the intensity of the light to which it is exposed, and varying with that with extreme sensibility; this has been experimented upon by Herr Werner Siemeus, of Berlin, a communication as to which he has addressed to the Academy of Sciences of that city, and of which some notice will be found in Nature for Dec. 9tb, 1875, p. 112

In conclusion, I may remark that nne of the ahlest oculistis practising in London has assured me that the construction of an efficient photostat would confer a valuable boon upon his profession, and great. y relieve much human suffering. Comprative diagnoses of the power of vision of the same eye made at successive intervals must be sulject to error where the same intensity of light cannot be insured for each examination.

Westminster Chambers, June 30th, 1876.

Mr. Hitchiss, medical officer of health for Westonsuper-Mare, reports that the health of that town is now exceptionaliy good. There has been very little sicknees during the past. quarter, and the mortality for the pericd was only 1076 per thousand. The total births in the quarter had been 89 , and the deaths (including those of visitore) 39.

\section{A}

\section{HOS PITAL PRACTICE, BRITISH AND FOREIGN.}

Nulla autem est alia pro certo noscendi via, nisi quamplarimas et morborum t dissectionum historias, tum alioram, tam proprias collectas habere, ox inter se comparare.-Mongagri De Sed. et Caus. Morb., lib. iv. Proceminm.

\section{LONDON HOSPITAL.}

STRANGULATED INGUINAL HERNIA; OPERATION; RE COVBRY.-STRANGULATED HERNIA; REDUCTION EN MASSE ; OPERATION ; RECOVERY.-CLINICAL REMARKS.

(Under the care of Mr. Maunder.)

For the notes of the subjoined interesting and instructive case we are indebted to Mr. E J. Lawless.

William C-, aged thirty-four, was successfulls operated upon by Mr. Maunder ten years ago for strangulated inguinal bernia of the left side. Since that time there has always been a sinall bubonocele on the same side, enlarging occasionally, hut always easily reduced by the patient himself. He wnre a truss, but left it off on finding the hernia atill descended behiud it. On May 22 ad, 1876, the hernia descended, while be was at work, two or three times. On each occasion he put his hand down, gave it a touch, and it went back, but he noticed that the tumour disappeared in a somerliat unusual manner; to use his own expression "it went up with a hang, and so quickly that I thought my bead was off." This reduction ufforded him no relief; he sonn began to vomit, and continned to do so all night. On the murning of May 23rd be applied to a doctor, who gave him some pills and a dranght, both of which his stomach rejected. He was then admitted into the hospital.

On examination tbere was no tumour in the inguinal cavd, and, with the exception of a large external ring, no evidence that, a hernia had existed. 'The man lay extended in bed, complained of some disconfort in his left groin, and vomited uccasionaly. There was a scar at the site of the former operation. Mr. Maunder advised inmediate ex. ploration, and the man at once consented.

An incision about two iaches in length was made just above and parallel to Poupart's ligament, and close to the scar of the former operation. The inguinal canal was quickly laid open, but no evidence of hernia could be seen until, on further dissection, a kind of pouch in the areolar tissue was opened. Hele the structures were slightly odematoue, and the finger carried to the depths of the wound detected a firm resisting swelling occupying the iliac fossa. On holding the edges of the wound apart, and carefully cleansing it, an opaque, pearly membrane was sen-the sac. A small puncture was made in this, and several onners of disccloured sernm escaped. The eac now became fluccid, and could be dragged readily out at the wound. It was then laid open, and a knuckle of bighly cougested intestine (strangulated twenty hours) was er. posed, tightly constricted. The stricture was relieved in the usual way, and the bowel was returned in to the eavity of the helly. A large extent of sac remained to be dealt witb, and the greater part of this was cut away and allowed the neck to drop back in ${ }^{\circ}$ the wourd. The incision was closed by suture, and a compress and bandage applied. Ordered to take calomel and opium freely; and shonld symptoms of peritonitis arise, veneseotion to be performed to ten ounces.

May 24th - Passed a comfortable night, with the exception of an occasional vomit (chloroform).

25 h. - Progressing favourably.

26 th.-Bowels have been moved; the stitches have been removed, and some redness has appeared on the outer side of the wound. To take opium at longer intervale, to omit the calomel, and to have six ounces of wine.

30th. - The redness has disappeared, and the patient is doing well.

June 17 th.-The patient is now convalescent.

Clinical remarks - Mr. Maunder said that all who gan the 